\title{
The driest continent and the greediest water company: newspaper reporting of drought in Sydney and London
}

\author{
Sarah Bell \\ Department of Civil, Environmental and Geomatic Engineering \\ University College London \\ Gower St, London WC1E 6BT, United Kingdom \\ phone $+44(0) 2076797874$ \\ fax $+44(0) 2073800986$ \\ s.bell@ucl.ac.uk
}

Abstract

Analysis of press reports of the onset of drought in Sydney in 2002 and London in

2006 shows different understandings of the relationship between infrastructure

provision, individual behaviour and the environment. Drought is both a natural and

cultural phenomenon requiring urban water managers to consider social as well as technical considerations in preparing for future droughts.

Keywords: Drought, urban, water infrastructure, media discourse

Word count: 3,844 


\section{Introduction}

Water infrastructure is usually invisible to the citizens of a city. Drought disrupts the operations of urban water systems. During drought, water systems become the subject of public controversy. Media reporting of drought reflects and shapes public understanding about the water system and its connections to the natural environment. Comparing media reporting (specifically, newspapers) of onset of recent droughts in Sydney and London helps to show how the public understands drought as a cultural and institutional, as well as natural, phenomenon.

This paper presents the results of systematic analysis of newspaper reporting of the first six months of drought in Sydney in 2002 and London in 2006. The paper aims to highlight the cultural and institutional aspects of drought in these two different cities. [OMIT - This demonstrates the importance of a more holistic understanding of drought by water managers, to complement more conventional technical and hydrological analysis. OK ]

\section{Drought in the city}

Drought is an extended period when rainfall is less than expected and is insufficient to meet normal human water needs [1]. This was evident across Europe in 2005 and 2006 and in Australia for most of the first decade of the $21^{\text {st }}$ century. Drought is usually considered as a rural issue [1-3], but is of increasing importance in urban contexts.

Drought [OMIT has been associated with discourses of scarcity ][Most readers of this journal will not understand your use of discourse. $\mathrm{OK}]$ in cities provides impetus for 
institutional reform and infrastructure expansion. Maria Kaika's [4, 5] analysis of the 1989-1991 Athens drought shows how the co-incidence of natural and political 'crises' led to water being represented as a scarce resource enabling the passage of highly controversial emergency reforms. These included a new water pricing scheme and the approval of an ecologically controversial new dam, and opened the way for further privatisation of Athens' water system. Leonard Nevarez' [6] account of the Californian drought of 1985-1991 demonstrates how that crisis resulted in previously averse South Coast residents voting to connect to the state water grid.

Karen Bakker's [7] detailed depiction of the Yorkshire drought of 1995 highlights the importance of relationships between institutional, managerial and hydro-ecological factors in producing drought and water scarcity. The Yorkshire drought was the first serious challenge to the fully privatised water industry in England and Wales, and the failures of Yorkshire Water in resource and demand management resulted in a significant re-regulation of the industry. Haughton [8] analysed media coverage of the Yorkshire drought, concluding that it represented a crisis of governance which galvanised pubic opposition to the privatisation of the UK water industry and called into question neo-liberal reform of natural resource management.

Downing and Bakker [9] make the case for discourse analysis in complementing more quantitative studies of drought vulnerability. They argue for rigorous analysis which moves beyond the idea of discourse as simply 'ways of talking about the world'. [Here, discourse is tightly defined $\&$ relevant.] They highlight the value of research which attempts to 'understand the various relationships, institutions, and 
socio-ecological configurations from which drought emerges and that drought reinforces and destabilises' [10].

[This is not really an analysis of the media: no reference to t.v. \& radio reports. Press therefore serves as a better term. Yes, I agree]

This paper compares press discussion of drought in Sydney and London in order to understand how relationships between institutions, climate and culture produce different experiences and understanding of drought. This analysis aims to provide a qualitative assessment of cultural responses to drought, distinct from conventional quantitative analysis, but providing useful perspectives on managing future urban water systems.

\section{Drought in the news}

This paper analyses newspaper reports of drought in Sydney and London. For Sydney reports of drought in The Sydney Morning Herald and the tabloid Daily Telegraph between July and December 2002 were analysed. For London The Guardian and The Daily Telegraph, and tabloids The Sun and Daily Mail, were analysed between January and June 2006. The newspapers were chosen for the diversity of coverage and readership, rather than as examples of 'high quality' reporting.

Media reporting of drought is increasingly important in shaping public understanding of climate change and environmental issues [11]. The analysis aims to show how the public understand drought, not to assess whether the press reports the 'facts' of drought accurately. [Here media serves as a general context, of wh press is the chosen example. Yes.] 
Drought management requires both major investment in infrastructure and reduction in water consumption. The public are important partners in preparing for drought and responding to it. The media reflect and shape how the public understand drought. It is important for managers of water systems to understand how drought is discussed in the media and presented to the public. Newspaper reports provide a useful record of public discussion and debate which reflects wider social and cultural considerations which may be overlooked in expert-led management of water systems. A comparative analysis of drought reporting can provide insights into popular understanding of the relationship between water, infrastructure and consumption.

London and Sydney provide useful case studies for comparison because of the differences in climate, water supply systems, institutional arrangements, domestic consumption and culture. Annual average rainfall in the Sydney water supply catchment is approximately $830 \mathrm{~mm}$ [12] and in London approximately 700mm [13]. Sydney's rainfall is more variable than London's as reflected in the volume of water stored in the supply system. Sydney's water supply is mainly from big dams which store up to 2.5 million megalitres [14]. London's supply is mainly abstracted from the Thames and other rivers, supplemented by ground water, with approximately 200,000 megalitres in storage [15]. Sydney's water system is government-owned with water resources managed by the Sydney Catchment Authority and treatment and distribution provided by the Sydney Water Corporation, which is owned by the State of New South Wales. London's water utility, Thames Water, is privately owned. Thames Water's abstractions from the environment are regulated by the Environment Agency, and pricing and investment are regulated by Ofwat (The Water Services Regulation Authority). Average daily per capita domestic consumption in Sydney is around 280 
litres [16], compared to 160 litres in London [17], reflecting differences in urban form, housing stock and rainfall patterns, as well as culture. External water use, including gardening, external cleaning, swimming pools and water features, accounts for an average of 70 litres per person per day in Sydney [18] compared with 10 litres per person per day in London [19]. [External = ? use of swimming pools? A reader mt suppose that some idea of personal hygiene via bathing was in issue. This needs explanation.] The newspaper reports analysed here concern 1 in 100 year drought events in both cities, but show contrasting responses to how water shortages are understood by the public and how they respond.

\section{Drought in Sydney}

Drought is a prominent part of Australian culture. Australian poetry talks about a land of 'drought and flooding rain', paintings such the 'Spirit of the Drought' by the nineteenth century artist Arthur Streeton portray drought as a fundamental part of the Australian landscape, and surviving drought is an important constituent of colonial Australian mythology $[20,21,22]$. The recent Australian drought has prompted debate about learning to live in the landscape and learning to live with drought as part of life [23]. This is mostly discussed in terms of farming systems, because it is the agricultural impacts of drought that are prominent in Australia, but there is equivalent impact on urban settlements $[24,25,26]$.

Drought was a major news story in Sydney in the second half of 2002. Newspapers were filled with photographs and stories of farmers and rural communities battling the worst drought in 100 years. Amongst the coverage of the agricultural drought were stories about the impact of drought on Sydney and the need for Sydney residents to 
conserve water. Discussion of drought in Australia consistently emphasized that Australians should realise that they live on the 'driest inhabited continent' on the planet, as highlighted by government ministers during the onset of drought in Sydney. At the end of National Water Week yesterday, the Minister for Energy, Kim Yeadon, said: "Nothing takes away from the fact that we live in the largest city on the world's driest continent". [27]

Consistent repetition in the press of the message that Australia is the world's 'driest inhabited continent' (despite Sydney receiving in excess of $1200 \mathrm{~mm}$ annual rainfall) provided the backdrop for commentators and reporters to moralise about wasteful water use.

The introduction of voluntary water restrictions in Sydney, Illawarra and the Blue Mountains from today is a reflection of our appalling selfishness at a time when drought has devastated the country...

In this time of drought, we should not need to be told to conserve water. It is to our shame that this has become necessary. [28]

Such moralising in the press about the wastefulness of Sydney water consumption was contrasted with the stoic struggles of rural Australians who bear the full brunt of drought on their livelihoods and lifestyles [29].

Compulsory restrictions on water use were introduced in September 2003 and were gradually stepped up as the drought continued. Discussions of water restrictions in Sydney were clearly linked to reporting of dam levels, making the link between water storage and supply, and household water consumption. Reporting of the vast scale 
[NOT enormity: Japanese war crimes are an enormity; the enormous scale of

Singapore's need for water before surrender is something else.] of Sydney's water storages, designed with drought in mind, showed the long-term planning and investment behind Sydney's water system [30]. Reports of water storage levels, including photographs of reservoirs and dams, reinforced the dominance of what Zoe Sofoulis [31] calls 'Big Water' in the management of water in Australia. 'Big Water' refers to the large engineering schemes and corporate-technocratic management organisations extracting and delivering water through centralised infrastructure systems, without consideration of the particular needs of household consumers. While chastising wasteful water users the press favourably reported on the effectiveness of drought planning by 'Big Water' managers and the government, including efforts to avoid compulsory restrictions unless essential [32].

The drought in Sydney continued for several years, resulting in a fall in storage levels, progressive tightening of restrictions and controversial decisions to increase supply through water transfers and desalination. The press focused at first on reducing demand by changing consumer behaviour, then shifted to the question of increasing supply as the drought continued. Between 2003 and 2008 water was transferred from the Shoalhaven River to Sydney's Waragamba Dam, providing up to $30 \%$ of supply but with controversial ecological impacts on the river system. Desalination was a highly controversial supply option which was approved in 2005, then put on hold in 2006 when new groundwater supplies were developed, and finally contracts were awarded for the construction of a desalination plant in 2007 to commence operation in 2009. As the drought worsened in Sydney political and engineering management of 
water infrastructure was the subject of intense public debate, but in the early years of the drought, analysed here, public discussion focused on individual consumers.

Early reporting of drought in Sydney provided a clear link between the infrastructure of 'Big Water' and the private behaviour of individual citizens. In the early years of the drought infrastructure management was rarely questioned in the press, but individual values and behaviour were subject to intense scrutiny. Even the news that average per capita consumption had decreased by $35 \%$ in the previous 20 years, was presented as only a start on the way to householders reducing their consumption by installing water saving showerheads and other devices [33]. Within the press discussion [OMIT dominant discourse about drought $\mathrm{OK}]$, any evidence of the longterm reduction in water usage by the average Sydney resident was overwhelmed by the message that restrictions were required because water use remained unacceptably high.

The moral push for water conservation was supported by institutional planning, technical advice to homeowners and the promotion of alternative sources of water including rain water harvesting and grey water reuse. Reducing demand for water was presented as a central feature of water planning, with targets set to reduce per capita consumption by one third over 20 years to avoid building a new dam [34]. The media coverage of the drought in 2002 included a number of references to how individuals could save water and how Sydney Water would help retrofit water saving devices in households. Tips for householders included changing behaviour such as turning the tap off while brushing teeth and taking shorter showers. Gardening and home feature 
pages provided advice on mulching and selecting drought tolerant plants, as well as using rain and grey water on gardens.

The question of whether or not water conservation requires major lifestyle changes was unresolved. [Are those changes NOT major for affluent, technologically rich people? Radical water conservation could mean major lifestyle change, for instance a compete change in gardens and gardening, drastically reducing the frequency of bathing or washing clothes, implementing composting toilets etc] The hardest moral line in the press called for city residents to change their lifestyles radically while Sydney Water and the government were careful to explain that new water saving devices and other technological changes would achieve water savings without radically changing Sydney lifestyles. The press's discussion highlighted individual responsibility for drought, but they rarely questioned the design and management of the central water system during this early period. Nor did the press challenge much the argument that there were benefits to individuals from changing behaviour, retrofitting their bathrooms and installing systems for rain and grey water.

In Sydney in 2002 the press presented the fact of drought as a natural feature of the world's 'driest inhabited continent'. Drought was a matter of wasteful water use by urban consumers. Private consumption was linked to water infrastructure as water restrictions come into force triggered by decreasing water storage levels. During the early years of the drought the press never questioned the institutional and technical management of this infrastructure, and individual water saving was presented as a moral obligation for urban Australians. [I think THIS para does what the previous one does; $\&$ therefore we can cut the previous one. OK ] 


\section{Drought in London}

In contrast to the rural focus of the Sydney press during the onset of drought, the London press reported drought as an overwhelmingly urban event. The reporting of rural hardship ahead of any impacts on urban water systems in Australia, the high levels of water storage in the system and popular messages about living in the "driest continent' provided a temporal, technical, and cultural buffer to drought in Sydney. After months of the worst drought for one hundred years, Sydney residents were only subject to voluntary water restrictions. By contrast drought was a relatively minor news story until London residents were faced with a hosepipe ban and the prospect of water rationing if the dry weather continued through the summer.

The cultural association of London with consistent rain contributed to a general scepticism that drought was an entirely natural phenomenon. Even when the image of the rainy city was challenged, the privatised ownership and management of London's water infrastructure provided further basis for public suspicion that drought was the result of mismanagement of water resources rather than inadequate supply, for example:

So this supposedly rain-sodden nation prepares for what some fear will be the most severe drought in a century, brought on by two exceptionally dry winters.

Clearly this isn't as damp a land as we sometimes think. While it pours in the North, Southern and Eastern England are among Europe's driest regions.

London, for example, has less rainfall than Algiers. 
But we can't blame nature when human folly, short-sightedness and greed play such a part in our predicament. [35]

Despite statistical assurance of 16 months of low rainfall and the driest weather for 100 years the London press resisted accepting drought as a purely natural phenomenon and focused on the role of technical and institutional factors in London's water system.

Drought discussion in London centred on leakage in the pipe network and the management of the private water company owning the system. The overwhelming response to Thames Water's announcement of a hosepipe ban was for the press to focus on the volume of water leaked from its London distribution network. The leaking pipes featured heavily in reports about drought. The press built up the view that water shortage in London was a problem of management, not merely rainfall deficiency.

Britain's ancient water pipes are in a terrible state. In London, more water is 'lost' into the soil than actually reaches the taps. When the water industry was privatised 17 years ago, share-buyers were offered the new companies at a whopping discount by the Tory government...

...Water bills are sky-high, fat-cat chairmen of the water firms are making millions - so why should we turn off our hosepipes, let our gardens die and share a bath with a friend while leaks are responsible for more than 30 lost gallons for every household in Britain? [36] 
While London householders largely complied with the restrictions, the media portrayed a high degree of resentment at the ban. The focus of this resentment was the water company, rather than the economic regulator Ofwat who oversee their investment strategies and business plans including targets for investment in leakage reduction. During the drought Thames Water's profitability was portrayed as greediness. Their continual failure to meet the targets that they agreed with Ofwat for reducing leakage in London was used as further evidence of their corporate greed rather than the failure of the institutional arrangements which underpin monopoly private ownership of water infrastructure. Whilst escaping the brunt of public outrage about drought restrictions, Ofwat were criticised for not using their powers to compel water companies to increase infrastructure investment [37].

Water shortages were also blamed on the absence of water meters across much of London, further highlighting policy and management rather than rainfall or culture deficiencies in causing and managing drought.

While privatisation is blamed by some commentators, others pin the current crisis on timid governments of both stripes which have refused to introduce the nationwide metering that is used to price and ration the use of every other essential resource.

John Blundell, director general of the Institute of Economic Affairs, says: "This 'shortage' is entirely contrived. It is bogus. It is achieved by our leaders being frightened to price something that is valuable and semi-finite". [38] 
The drought prompted some discussion of the potential for future water shortages in a region with a growing population and growing water demand per capita. Some attention was directed to water conservation in the home and garden, although more attention was given to the construction of a national water grid [39].

The main impact of drought on Londoners was the hosepipe ban, which impacted on gardeners specifically. The head of the Environment Agency called on gardeners to be the vanguard of water conservation, and gardeners provided the strongest sign of individual behaviour change in response to drought [40]. Gardening tips in the London newspapers were much more pragmatic in their guidance for helping to save plants during the hosepipe ban [41], compared with a much greater cultural and moral significance attached to changing gardening practices in Sydney. [Please re-writenot clear. How is reducing usage in Sydney not pragmatic? I have re-written the sentence as requested]

Although largely focused on drought as an institutional affair, reporting of the 1976 drought reminded London that drought is possible and can severely disrupt everyday practices. Stories about the 1976 drought warned of the implications of serious water shortages, demonstrated that many of the current issues, including water metering and calls for household constraint, are not new, and provided a contrast between institutional arrangement and cultures pre- and post- privatisation. Reminiscence of 'the spirit of the Blitz' as Londoners pulled together to survive the 1976 drought was contrasted with the indignation of customers forced to restrict use while water company shareholders received dividends [42]. 
Reporting of increased water consumption and changing household technologies and behaviours drew attention to the contribution of individual consumption to water shortages.

But as reservoirs and underground water sources empty and supplies dwindle, demand is growing. Household water use has increased by more than half since 1971 and while the average person used 140 litres a day in 1993, that figure had fountained to 154 litres two years ago. [43]

This led to some recognition of the need for changes in household technologies in managing urban water shortages [44].

Reports about gardening and household consumption and technologies in London were presented as pragmatic responses to drought in London. [Not clear. The indignation opposed the needless restrictions to the uncurbed greed of profit-taking companies: i.e., there was moral outrage. Morality is apparent in both kinds of media reports. This is not an important point in this paragraph, hence I have deleted the reference to morality in Sydney here] This underlying pragmatism was demonstrated by Thames Water's statistics showing reduced consumption during the period of the hosepipe bans, despite the level of resentment and backlash against the company reported in the press [45]. Notwithstanding general compliance with the hosepipe ban and despite the efforts of the Environment Agency and water companies to quote rainfall statistics, the press in the first half of 2006 interpreted drought as an institutional rather than meteorological event. Reporting of drought in London focused on the failure of institutional actors, particularly private water companies and their regulators, to maintain the modern infrastructure which links the city and its hydro-ecological context. 


\section{Conclusion}

The purpose of this paper has been to analyse how urban water systems are represented in press reports on drought. Both Sydney and London were experiencing the onset of a 1 in 100 year drought event, yet press reporting showed very different understandings of the nature of drought in each city. In Sydney drought was presented as a natural feature of the 'driest inhabited continent' and responses to drought focused on the moral duty of individual householders to reduce consumption. In London water shortages were presented as the result of profit-taking and underinvestment in infrastructure by the private water company, rather than a natural event which individuals must respond to. Morality was at stake the reporting of drought in both cities. The London press expressed moral outrage at the poor maintenance record and profit-making of the private water company, while moral outrage in Sydney was focussed on the wastefulness of private householders, particularly in comparison to the hardship experienced by their rural counterparts. This comparison shows that the public understand drought as a cultural and institutional, as well as technical and hydrological event.

Institutional arrangements or cultural norms that are taken for granted during periods of high or average rainfall are scrutinised by the press during drought. In the immediate circumstances of a particular drought event managing media relations is a difficult task for water utilities. Analysis of reporting after the event provides useful qualitative data about how the public understand their water systems and how they explain drought. In Sydney this highlights the opportunities for water managers to support changing cultures of water consumption, and in London it showed that it was 
important for Thames Water and Ofwat to solve the problem of leakage before the public will accept responsibility for managing resources by reducing household water use.

The analysis of media reporting of drought highlights the importance of good management of water infrastructure and resources for cities. During drought water consumption, water infrastructure and water managers come under scrutiny. Under normal rainfall conditions water systems receive relatively little press coverage or public attention, but this is when drought management planning and preparations are undertaken by water managers. Reports of the recent droughts in Sydney and London suggest that water managers should ensure that leakage and wastage in their networks are minimised to avoid public backlash against water restrictions and to conserve water resources, and that efforts to achieve cultural change to reduce water consumption are supported by effective technological innovation in water efficiency and alternative water sources such as rainwater harvesting and grey water recycling. As well as improving drought management, such technologies should also be integrated into stormwater management techniques to deliver more sustainable urban water systems [46]. 


\section{References}

[1] Botterill, L. C. and Fisher, M., 2003 Beyond Drought (Melbourne: CSIRO Publishing).

[2] Wilhite, D., Easterling, W. and Wood, D., 1987, Planning for drought: towards a reduction of societal vulnerability (London: Westview).

[3] Wilhite, D., 1993. Drought Assessment, Management and Planning: Theory and case studies (Boston: Kluwer Academic Publishers).

[4] Kaika, M., 2003, Constructing Scarcity and Sensationalising Water Politics: 170 Days the Shook Athens, Antipode, 35 (5), 919-954.

[5] Kaika, M., 2006, The political ecology of water scarcity: The 1989-1991 Athenian drought, in: N. Heynen, M. Kaika and E. Swyngedouw (Eds) In the nature of cities (London: Routledge), pp. 157-172.

[6] Nevarez, L., 1996, Just wait until there's a drought: mediating environmental crises for urban growth, Antipode, 28 (3), 246-272.

[7] Bakker, K, 1999, Deconstructing discourses of drought, Transactions of the Institute of British Geographers, 24, 367-378.

Bakker, K., 2003, An un-cooperative commodity: privatizing water in England and Wales (Oxford: Oxford University Press).

[8] Haughton, G., 1998, Private profits - public discourse: the creation of a crisis in water management for West Yorkshire, Transactions of the Institute of British Geographers, 23, 419-433.

[9] Downing, T. and Bakker, K., 2000, Drought discourse and vulnerability, in: D. Wilhite (Ed) Drought. Hazards and disasters: A series of definitive major works (London: Routledge), pp. 213-230.

[10] Downing and Bakker, 2000, pg. 227, Op Cit., note 7. 
[11] O'Donnell, C. and Rice, R., 2008, Coverage of environmental events in US and UK newspapers: frequency, hazard, specificity and placement, International Journal of Environmental Studies, 65 (5), 637-654.

[12] National Water Commission, 2005, Sydney Water Supply Area, Regional Water Resource Assessment - Capital city, Australian Water Resources 2005, Australian Government, available on-line http://www.water.gov.au/RegionalWaterResourcesAssessments/SpecificGeographicR egion/TabbedReports.aspx?PID=NSW_SW_213x, last accessed $15^{\text {th }}$ June 2009. [13] Meteorological Office, 2009, Greenwich 1971-2000 averages, Met Office UK, http://www.metoffice.gov.uk/climate/uk/averages/19712000/sites/greenwich.html, last accessed $15^{\text {th }}$ June 2009.

[14] Sydney Catchment Authority, 2009, Major SCA dams, Sydney Catchment Authority, New South Wales Government, http://www.sca.nsw.gov.au/dams-andwater/major-sca-dams, last accessed $15^{\text {th }}$ June 2009.

[15] Thames Water Utilities Limited, 2008, Volume 2 - Main Report, Water planning for the future. Draft Water Resources Management Plan (Reading: Thames Water Utilities Limited), available on-line http://www.thameswater.co.uk/cps/rde/xchg/corp/hs.xsl/5373.htm, last accessed $15^{\text {th }}$ June 2009.

[16] Troy, P., 2008, Trouble Waters (Canberra: ANU E-Press), available on-line http://epress.anu.edu.au/troubled_waters_citation.html, last accessed $15^{\text {th }}$ June 2009. [17] Thames Water Utilities Limited, 2008, Op Cit., note 15.

[18] Troy, 2008 Op Cit., note 16.

[19] Thames Water Utilities Limited, 2008, Op Cit., note 15. 
[20] Bonyhady, T., 2001, The Colonial Earth (Melbourne: Melbourne University Press).

[21] West, B. and Smith, P., 1994, Drought, discourse and Durkheim: a research note, Australia and New Zealand Journal of Sociology, 32 (1), 93-102.

[22] Ward, R., 1966, The Australian Legend (Melbourne: Oxford University Press).

[23] Bell, S. and Moller, M., 2006, The green drought, Australian Humanities Review 38, available on-line http://www.lib.latrobe.edu.au/AHR/archive/Issue-April2006/EcoBell.html, last accessed 2 January 2007.

[24] Day, D., 1987, An Australian perspective on drought and water management objectives for regional development, Water Resources Development, 3 (4), 266-283. [25] Mules, W., Schirato, T. and Wigman, B., 1995, Rural identity within the symbolic order: media representations of the drought, In: P. Share (Ed) Communication and culture in rural areas (Wagga Wagga: Centre for Rural Social Research, Charles Sturt University), pp. 239-257.

[26] Wahlquist, A., 2003, Media representations and public perceptions of drought, In: L.C. Botterill and M. Fisher M. (Eds) Beyond Drought (Melbourne: CSIRO Publishing), pp. 67-86.

[27] Peatling, S., 2002, Saving schemes will hold water, The Sydney Morning Herald, 26 October, p.5.

[28] Daily Telegraph, 2002, Drought and our shame, Daily Telegraph (Sydney), 15 November, p.28.

[29] Benson, S., 2002, Today each home will use more than 900 litres of water, Daily Telegraph (Sydney), 15 November, p.29.

[30] Macey, R. and O'Malley, N., 2002, Water in the bank, but don't splash out, The Sydney Morning Herald, 20 November, p.3. 
[31] Sofoulis, Z., 2005, Big Water, Everyday Water: A Sociotechnical Perspective, Continuum: Journal of Media and Cultural Studies, 19 (4) 445-463.

[32] Skelsey, M., 2002, Sydney's reprieve in water restrictions, Daily Telegraph (Sydney), 1 November, p.11.

[33] Sheehan, P., 2002, Fire and water the bane, and the salvation, of our existence and survival, The Sydney Morning Herald, 9 December, p.13.

[34] Peatling, S., 2003, Water tank scheme in danger of trickling out, The Sydney Morning Herald, 21 May, p.5.

[35] Daily Mail, 2006, Why rainy Britain is running dry, Daily Mail (London), 16 May, p.14.

[36] Hanlon, M., 2006, If we're such a wet country where has all the water gone? Daily Mail (London), 3 March, p.14.

[37] Levy, A., 2006, As the water bans bite $£ 2$ bn profits pour in, Daily Mail (London), 15 May, p.26.

[38] Stevenson, T., 2006, Heat and cold fuel bills, Daily Telegraph (London), 1 June, p.4.

[39] Poulter, S., 2006, Only a national water grid will spare the South from years of drought bans, warn engineers, Daily Mail (London), 27 June, p.23.

[40] Murray-West, R. 2006, Blooms that are bred to beat the hose ban, Daily Telegraph (London), 24 April, p.3.

[41] Don, M., 2006, Home and dry, Daily Mail (London), 29 April, p.80.

[42] Hanlon, M., 2006, When life was really hot, Daily Mail (London), 15 June, p.22.

[43] The Sun, 2006, Threats of meters as companies pour $£ 3 m$ worth of water a day down the drain, The Sun (London), 3 March.

[44] Hastings, M., 2006, A world running dry, Daily Mail (London), 21 January, p.16. 
[45] Thames Water, 2006, Waterwise customers are helping to beat the drought, Press

Release, 17 August.

[46] Yu, X., 2008, Use of low quality water: an integrated approach to urban stormwater management (USM) in the Greater Metropolitan Region of Sydney, International Journal of Environmental Studies 65 (1), 119-137. 